\title{
On the statistical relationship between cloud optical and microphysical characteristics and rainfall intensity for convective storms over the Mediterranean
}

\author{
E. Cattani, F. Torricella, S. Laviola, and V. Levizzani \\ Institute of Atmospheric Sciences and Climate, National Research Council, ISAC-CNR, Bologna, Italy \\ Received: 1 April 2009 - Revised: 10 December 2009 - Accepted: 10 December 2009 - Published: 23 December 2009
}

\begin{abstract}
The relationship between the multi-spectral cloud field characterization from the Advanced Very High Resolution Radiometer (AVHRR) and the rainfall intensities from the Advanced Microwave Sounding Unit-module B (AMSU-B) data were studied for a convective storm event, which occurred during the first 15 days of June 2007 over the Mediterranean. The cloud products exploited in this analysis, cloud mask, type, optical thickness, and effective radius, are obtained from the NOAA-NESDIS operational processing system Clouds from the AVHRR-Extended algorithm (CLAVR-x), whereas the rain intensity values are retrieved from the AMSU-B brightness temperatures via a fast algorithm, using opaque frequencies (centred at $183 \mathrm{GHz}$ ) to correct for the presence of water vapour affecting the retrieval results. The algorithm is conceived to discriminate between convective and stratiform rain using a suitable set of thresholds; the retrieval is subsequently carried out separately for the two types.
\end{abstract}

A test for the discrimination of precipitating from nonprecipitating areas was based on the comparison between the precipitation information and the retrieved cloud parameters. The test produced a cloud optical thickness threshold value, beyond which the precipitation initiates, and an effective radius range for the identification of the precipitating clouds. The results stemming from the application of the test to the June 2007 case study are very encouraging, although still preliminary and restricted to the analyzed Mediterranean storms. In particular, the test shows high potential for delineating non-precipitating areas (more than $90 \%$ of successful cases for every considered cloud type) and to identify precipitating ice clouds related to convective rain (confirmed by $82 \%$ of hits). On the other hand, the relative inability to address the stratiform cloud systems is proved by the fact

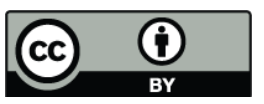

Correspondence to: E. Cattani (e.cattani@isac.cnr.it) that the majority of the missed cases, for each cloud types, is characterized by light rain intensities $\left(\leq 3 \mathrm{~mm} \mathrm{~h}^{-1}\right)$.

\section{Introduction}

Given the obvious strong links between cloud microphysical properties and precipitation, a more unified approach to observing cloud properties is necessary in order to improve the performances of the satellite retrieval algorithms and our knowledge of clouds and precipitation processes (e.g., Stephens and Kummerow, 2007). Recent studies have demonstrated the effectiveness of such an approach. Nauss et al. (2008) showed the effectiveness of the use of cloud properties derived from optical satellite data for the delineation of precipitation areas. Likewise, precipitation indices from visible, near infrared and infrared (VIS, NIR, IR) spectral features, tuned by means of co-located ground measurements of rain intensity (gathered from gauge or radar networks), showed a high correlation with precipitation and thus were used to derive precipitation likelihood (Thoss et al., 2001).

Torricella et al. (2008) analyzed the relationship between the rain area delineation by means of microwave (MW) channels of the Advanced Microwave Scanning Radiometer (AMSR-E) and the multi-spectral cloud field characterization from the Moderate Resolution Imaging Spectroradiometer (MODIS) cloud products. The analysis carried out over the Mediterranean region for the first 15 days of June 2007 demonstrated a clear positive correlation for ice clouds between rain intensity (RI) and cloud optical thickness $(\tau)$, and the presence of a threshold for rain initiation at an optical thickness of 40, whereas no clear relationship was found between cloud top effective radius $\left(R_{\mathrm{e}}\right)$ and RI. It was not possible to draw any conclusion for the raining water clouds due to their scarce number according to the AMSR-E retrieval algorithm.

Published by Copernicus Publications on behalf of the European Geosciences Union. 


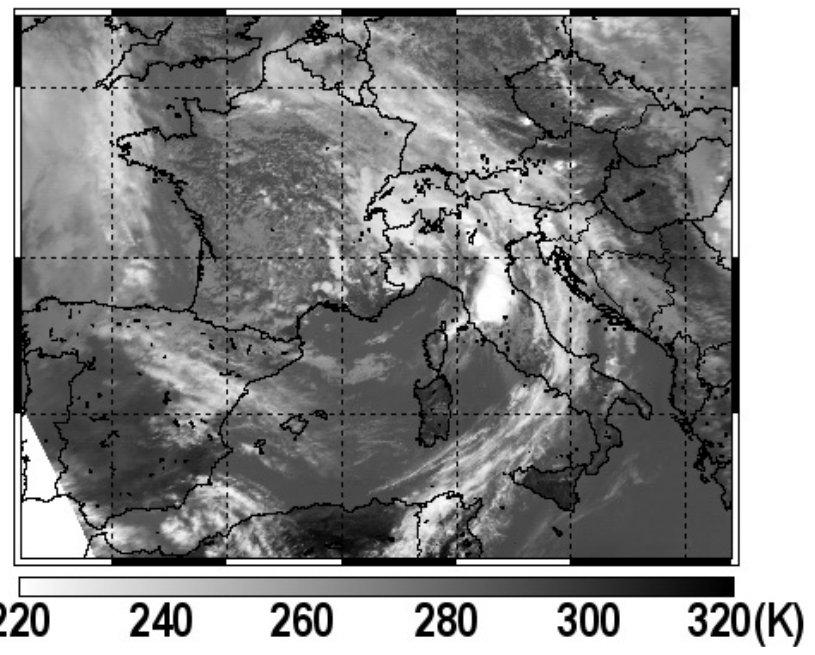

Fig. 1. 1 June 2007, 10:54 UTC. AVHRR (NOAA-18) brightness temperatures at $10.8 \mu \mathrm{m}$ over the selected area.

In this work the same methodology was applied to the 115 June 2007 case study, exploiting the cloud products from the Advanced Very High Resolution Radiometer (AVHRR) and the rain intensities retrieved from the Advanced Microwave Sounding Unit-module B (AMSU-B), to further investigate the statistical relationships between the cloud parameters and the rain intensity field.

\section{The case study}

The study is focused over the western Mediterranean basin, Italy, and Central Europe $\left(35^{\circ}-52^{\circ} \mathrm{N}\right.$ and $9^{\circ} \mathrm{W}-22^{\circ} \mathrm{E}$, see Fig. 1) for the first 15 days of June 2007. In this period, a very unstable weather characterized the whole region, particularly Italy. The most severe events took place during the first 10 days of the month, when a low-pressure system located over central-South Europe associated with cold air at high levels, fostered heavy thunderstorms and downpours on the 1 st and 2nd. On 7 June and, again, on 11th and 13th, the thunderstorms over the Italian peninsula intensified, with very high cumulated precipitation values and a strong lightning activity.

\section{Instruments and data}

The characterization of the cloudy scenarios was carried out by means of AVHRR cloud products of the Clouds from the AVHRR-Extended algorithm (CLAVR-x) at a spatial resolution of $4 \times 4 \mathrm{~km}^{2}$. The CLAVR-x is the operational processing system of the National Oceanic and Atmospheric Administration (NOAA) National Environmental Satellites, Data and Information Service (NESDIS) for detecting clouds from
AVHRR data and to derive the corresponding cloud properties (Heidinger, 2003; Pavolonis et al., 2005; for further details see also http://cimiss.ssec.wisc.edu/clavr). The cloudy pixels were selected using the cloud mask product, which reports 4 levels of probability (clear, probably clear, probably cloudy, and cloudy), whereas the cloud type product with the six cloud categories, fog, water, supercooled water, opaque ice, cirrus and multi-layer cloud, was exploited to pinpoint the cloud thermodynamic phase. The cloud optical thickness and effective radius products were utilized to complete the cloud characterization.

The rain intensities from the AMSU-B data were computed using the 183-WSL algorithm developed at ISACCNR (Laviola and Levizzani, 2008a, b). The rain rate intensities are inferred exploiting the perturbation induced by the rain drops onto the strong water vapour absorption band centred at $183.31 \mathrm{GHz}$. Since the $183.31 \mathrm{GHz}$ band is strongly dependent on the temperature and humidity profiles, a series of thresholds were computed in order to remove the areas characterized by the absorption of condensed water vapour and those interested by the scattering of snow, which could be erroneously classified as rain. The algorithm was also conceived to discriminate between convective and stratiform rain using a suitable set of thresholds. The spatial ground resolution of the derived rain product is $16 \times 16 \mathrm{~km}^{2}$.

For the present analysis the data from the AVHRR and AMSU-B sensors on board the NOAA-18 platform were exploited, thus ensuring simultaneous and co-located observations of the scenarios. Figure 2 shows an example of the AVHRR cloud products on 1 June 2007, 10:54 UTC. The rain intensity map retrieved by the 183-WSL algorithm for the same NOAA-18 overpass of Fig. 2 is presented in Fig. 3.

\section{Statistical analysis}

The statistical analysis was performed by processing all the data from the 28 daytime overpasses of the NOAA- 18 platform. The total numbers of the analyzed observations of the two instruments are summarized in Table 1. The AVHRR cloud mask product was used to identify the cloudy pixels, selecting only those pixels classified as probably cloudy or cloudy. The cloud thermodynamic phase was determined on the basis of the cloud type product. In particular, the cloud phase "water" (207 717 pixels) was attributed to the AVHRR cloudy pixels identified as covered by warm water clouds or supercooled water clouds according to the cloud type product. The ice clouds ( 72856 pixels) included opaque ice, consistently with deep convection, but also cirrus clouds. Finally, the overlapping clouds category, which is the most populated one (about $48 \%$ of the total AVHRR cloudy pixels), identifies situations in which more than one cloud layer is present. Rainy pixels represent about $7 \%$ of the total number of the AMSU-B observations. 


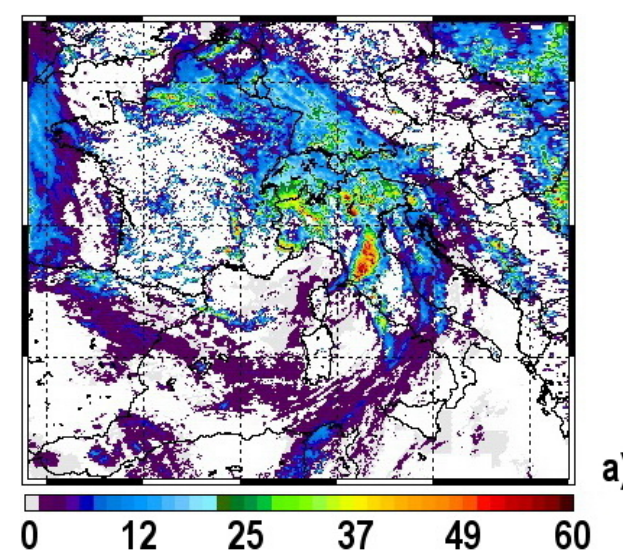

a)
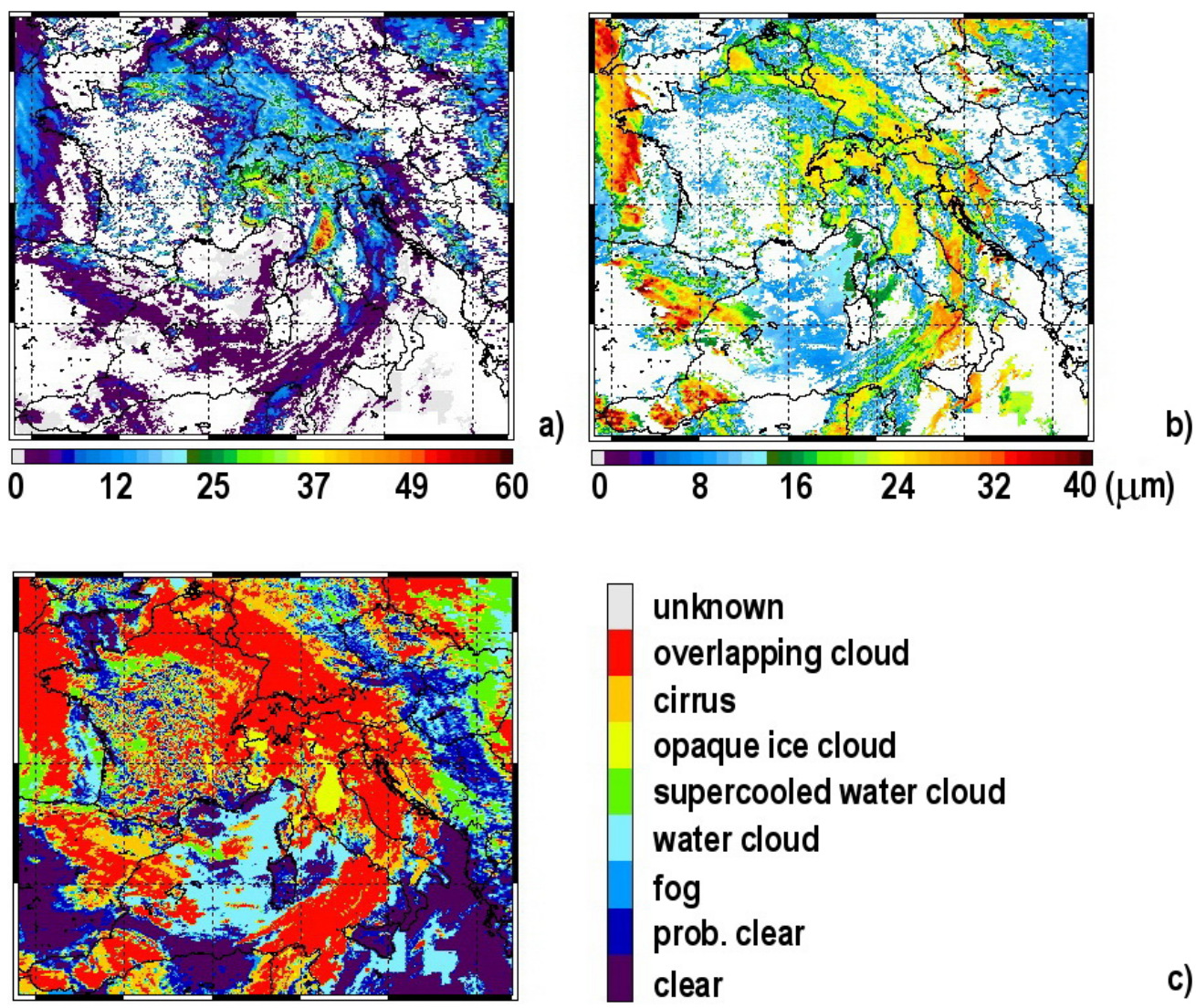

Fig. 2. 1 June 2007, 10:54 UTC. AVHRR cloud products used in the statistical analysis: (a) $\tau$, (b) $R_{\mathrm{e}}$, and (c) cloud type.

Due to the different spatial resolution of the AVHRR and AMSU-B derived products, all the data were re-projected over a common $0.1^{\circ} \times 0.1^{\circ}$ regular lat-lon grid, in order to establish the relationships between cloud parameters and rain intensity data. On average one AMSU-B and about 4 AVHRR pixels fell in each grid cell. Table 2 reports the statistics relative to the re-projected data. The percentages listed in the second column of Table 2 (except for the "rainy but clear" and the "cloudy" categories that refer to the total number of grid cells) are computed with respect to the number of cloudy grid cells. The number of the rainy grid cells and the corresponding percentages computed with respect to each subset of cloudy grid cells are reported in Table 2 as well. A grid cell was defined cloudy in the case where $70 \%$ of the AVHRR pixels falling within that grid cell were classified by the AVHRR cloud mask as cloudy. The same threshold $(70 \%)$ was applied to identify the other categories, i.e. cloudy grid cells over the sea, land, coast, covered by water, ice or overlapping clouds.

Clouds over land have the highest number of occurrences (59\% of the total number of cloudy cells) also owing to the much higher number of land cells in the analysed region. They are also the most raining (19.7\% of clouds over land are raining against $2.9 \%$ over the sea). Ice clouds show the greatest percentage of raining grid cells, whereas only a very low
Table 1. Number of observations (pixels) of the two instruments during the analysis period (1-15 June 2007). The data reported in the table are derived from the AVHRR CLAVR-x cloud products and the 183-WSL rain algorithm applied to AMSU-B data.

\begin{tabular}{lr}
\hline & \# pixels \\
\hline AVHRR & 899827 \\
cloudy & 543248 \\
$\quad$ ice clouds & 72856 \\
water clouds & 207717 \\
overlapping clouds & 262675 \\
over the sea & 192617 \\
over the land & 328881 \\
over the coast & 21750 \\
AMSU-B & 183147 \\
$\quad$ rainy & 12212 \\
\hline
\end{tabular}

percentage of water clouds $(0.8 \%$ of the number of the water cloud grid cells) are raining. Note that only 570 grid cells $(0.03 \%$ of the analyzed total number of grid cells) are classified as raining while being clear, demonstrating the effectiveness of the 183-WSL algorithm in discarding non-cloudy observations. 


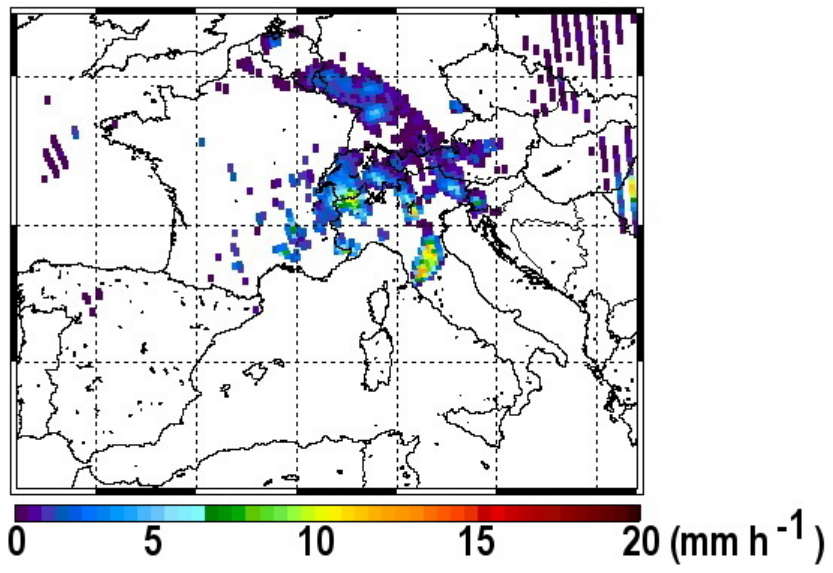

Fig. 3. 1 June 2007, 10:54 UTC. Rain intensity retrieved by the 183-WSL algorithm applied to AMSU-B brightness temperatures.

\section{Results}

The gridded data presented in the previous section were used to evaluate the possible relationships between rain intensity and $\tau$ and $R_{\mathrm{e}}$.

In Fig. $4 a-b$ the scatter plots of rain intensity against cloud optical thickness are shown for a) the ice cloud grid cells and b) for the overlapping clouds. The green symbols refer to the cloudy grid cells over land, whereas blue symbols represent those over the sea. The solid lines connecting the diamond symbols represent the 75th, 50th, and 25th percentiles. A positive correlation between rain intensity and optical thickness in the variability range of the data $(\tau \leq 60$ and $\mathrm{RI} \leq 20 \mathrm{~mm} \mathrm{~h}^{-1}$ ) is evident from the scatter plots. The binned analysis presented in Fig. 4c-d makes the relationship between rain intensity and optical thickness further stand out. This analysis was carried out by binning all rain data in $1 \mathrm{~mm} \mathrm{~h}^{-1}$ intervals and then averaging the corresponding $\tau$ values. With this kind of data visualization the relationship between rain intensities and $\tau$ is much more visible. Moreover, a threshold value of $\tau \sim 15$ beyond which precipitation is initiated, is evident as well. The agreement with the analogous plot for ice clouds of Fig. 2 b reported by Torricella et al. (2008) is good, except for the optical thickness threshold value $(\sim 40)$. This discrepancy is due to the fact that MODIS cloud optical thickness values are generally higher than those retrieved from AVHRR data: the mean optical thickness value from MODIS data is 25.11 against 9.38 for the AVHRR, whereas when selecting only precipitating cloudy grid cells the MODIS mean $\tau$ is 54.23, whereas for the AVHRR is about 20.
Table 2. Statistics of the analyzed grid cells for the whole study period. The percentages reported in the second column are computed with respect to the number of cloudy grid cells, with the exception of the "rainy but clear" and the "cloudy" categories that refer to the total number of the grid cells. The percentages of the rainy grid cells are relative to each subset of cloudy grid cells.

\begin{tabular}{lrcrc}
\hline & $\begin{array}{r}\text { \# grid } \\
\text { cells }\end{array}$ & $\%$ & $\begin{array}{r}\text { \# rainy } \\
\text { grid } \\
\text { cells }\end{array}$ & $\begin{array}{c}\% \text { rainy } \\
\text { grid } \\
\text { cells }\end{array}$ \\
\hline total & 1975428 & 100 & & \\
rainy but clear & 570 & 0.03 & & \\
cloudy & 89475 & 4.5 & 11642 & 13.01 \\
over the sea & 33031 & 37 & 948 & 2.9 \\
over the land & 52946 & 59 & 10448 & 19.7 \\
coast contam. & & & & \\
(discarded) & 3498 & 3.9 & & \\
$\begin{array}{l}\text { water clouds } \\
\text { ice clouds }\end{array}$ & 23435 & 26.2 & 187 & 0.8 \\
overlapping clouds & 4991 & 5.6 & 1387 & 27.8 \\
\hline
\end{tabular}

The relationship between the rain intensities and the corresponding $R_{\mathrm{e}}$ values is investigated in Fig. $5 \mathrm{a}-\mathrm{c}$, where the scatter plots for the AVHRR and AMSU-B data sets (Fig. 5a and $\mathrm{b}$ for ice clouds and overlapping clouds, respectively), and for ice clouds examined with the MODIS and AMSR-E data according to Torricella et al. (2008) (Fig. 5c) are shown. From these scatter plots it is evident that the AMSR-E derived rain intensities reach values much higher than the corresponding AMSU-B retrieved intensities. The scatter plots and the over-plotted $R_{\mathrm{e}}$ histograms show very similar trends regardless of the cloud type: the majority of the occurrences are accumulated in the $R_{\mathrm{e}}$ range between 20 and $30 \mu \mathrm{m}$, with which also the higher rain intensities $\left(\mathrm{RI} \geq 5 \mathrm{~mm} \mathrm{~h}^{-1}\right)$ are mainly associated. No analogous scatter plots for the water clouds are displayed due to the scarce number of raining water cloud grid cells, which are by no means enough for a meaningful statistic.

Thus a possible method to identify potentially precipitating cloudy pixels stems from the analysis of the relationships between $\tau, R_{\mathrm{e}}$ and rain intensities: when retrieving a $R_{\mathrm{e}}$ value between 20 and $30 \mu \mathrm{m}$ and a $\tau$ value greater than 15 (or 40 in case of MODIS cloud parameter data set) the pixel can be safely considered as raining.

All cloudy grid cells analyzed in this work have undergone this test on $\tau$ and $R_{\mathrm{e}}$, in order to evaluate the capability of the test in delineating the potentially precipitating areas. The results for the AVHRR and AMSU-B data set are summarized in Table 3, together with the corresponding results for the MODIS and AMSR-E data. The performances of the test were evaluated by means of the coefficients $a$, 


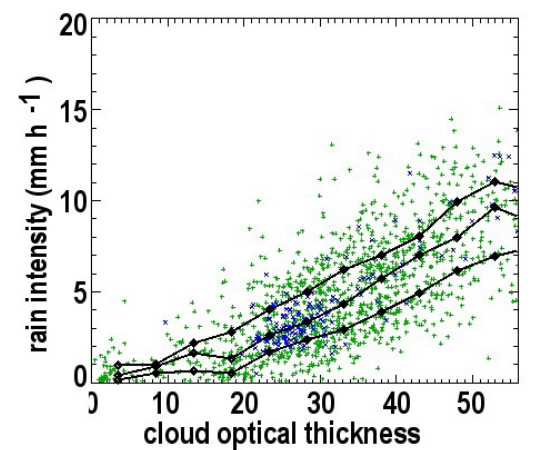

a)
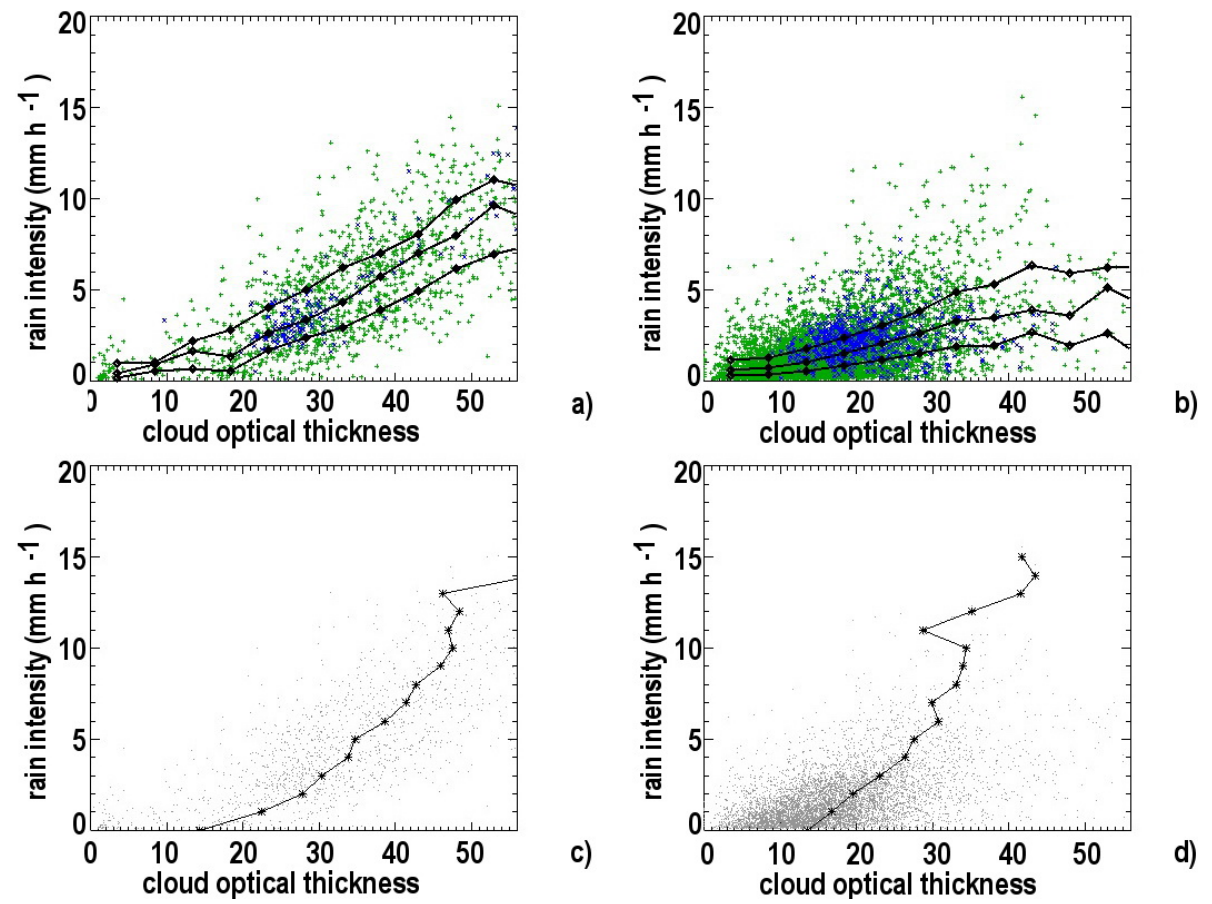

Fig. 4. Rain intensity as a function of cloud optical depth for ice cloud grid cells (a) and overlapping cloud grid cells (b). Cloudy grid cells over land and sea correspond to the green and blue symbols, respectively. Solid lines in (a) and (b) represent the 75th, 50th, and 25th percentiles. In (c) and (d) the results of the binned analysis are shown, carried out by binning all rain data in intervals of $1 \mathrm{~mm} \mathrm{~h}^{-1}$ and then averaging the corresponding $\tau$ values.
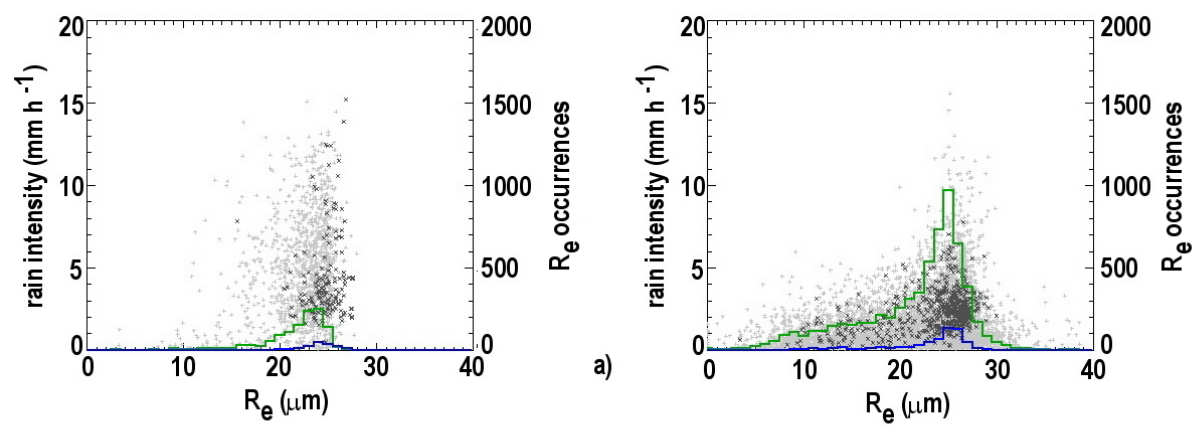

b)

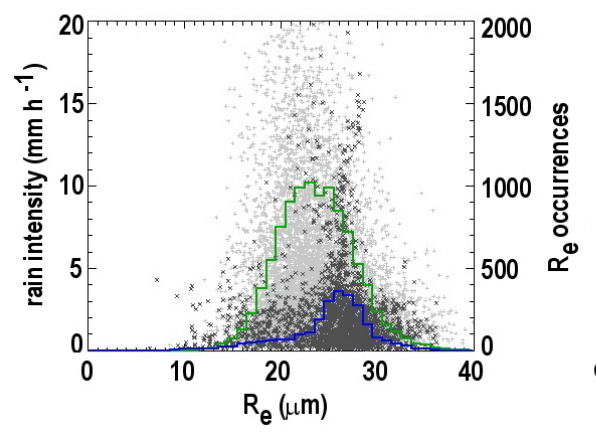

Fig. 5. Rain intensity (left Y-axis) as a function of $R_{\mathrm{e}}$ : light grey symbols refer to cloudy grid cells over land, whereas dark grey symbols represent those over sea. AVHRR-AMSU-B data are displayed in (a) and (b) for ice and overlapping clouds, respectively, MODIS-AMSR-E data for ice cloud grid cells are presented in (c). $R_{\mathrm{e}}$ histograms for clouds over land are in green, while in blue are represented those relative to cloud over sea. On the right Y-axes the number of $R_{\mathrm{e}}$ occurrences is reported. 
Table 3. Performances of the $\tau$ and $R_{\mathrm{e}}$ test: statistical parameters for the two data sets, AVHRR vs. AMSU-B and MODIS vs. AMSR-E and for the different cloud categories.

\begin{tabular}{lcccccc}
\hline & & \multicolumn{3}{c}{ AVHRR vs. AMSU-B } & \multicolumn{2}{c}{ MODIS vs. AMSR-E } \\
\cline { 3 - 7 } & Perfect score & ice & water & multi-layer & ice & water \\
\hline hits & - & $82 \%$ & $2 \%$ & $45 \%$ & $55 \%$ & $0 \%$ \\
misses & - & $18 \%$ & $98 \%$ & $55 \%$ & $45 \%$ & $100 \%$ \\
false alarms & - & $6 \%$ & $0 \%$ & $5 \%$ & $8 \%$ & 0 \\
correct negatives & - & $94 \%$ & $100 \%$ & $95 \%$ & $92 \%$ & $100 \%$ \\
POD & 1 & 0.820 & 0.016 & 0.448 & 0.550 & 0 \\
FAR & 0 & 0.161 & 0.880 & 0.273 & 0.278 & - \\
POFD & 0 & 0.060 & 0.001 & 0.049 & 0.079 & 0 \\
ACCURACY & 1 & 0.906 & 0.991 & 0.838 & 0.820 & 0.994 \\
\hline
\end{tabular}

$b, c$, and $d$ computed for the two data sets according to the definition given by Ebert (2005):

$$
\begin{array}{lc}
a=\text { hits } & \operatorname{rain}\left(\tau \geq \tau_{\text {thres. }} \text { and } R_{\mathrm{e}} \in[20,30] \mu \mathrm{m}\right) / \\
& \operatorname{rain}\left(\mathrm{RI}>0.1 \mathrm{~mm} \mathrm{~h}^{-1}\right) \\
b=\text { misses } & \text { no rain }\left(\tau<\tau_{\text {thres. }} \text { or } R_{\mathrm{e}} \notin[20,30] \mu \mathrm{m}\right) / \\
& \operatorname{rain}\left(\mathrm{RI}>0.1 \mathrm{~mm} \mathrm{~h}^{-1}\right) \\
c=\text { false alarms } & \operatorname{rain}\left(\tau \geq \tau_{\text {thres. }} \text { and } R_{\mathrm{e}} \in[20,30] \mu \mathrm{m}\right) / \\
& \text { no rain }\left(\mathrm{RI} \leq 0.1 \mathrm{~mm} \mathrm{~h}^{-1}\right) \\
d=\text { correct negatives } & \text { no rain }\left(\tau<\tau_{\text {thres. }} \text { or } R_{\mathrm{e}} \notin[20,30] \mu \mathrm{m}\right) / \\
& \text { no rain }\left(\mathrm{RI} \leq 0.1 \mathrm{~mm} \mathrm{~h}^{-1}\right) .
\end{array}
$$

From the combinations of these four elements the following statistical parameters were computed:

$$
\begin{array}{ll}
\text { POD (probability of detection) } & =a /(a+b) \\
\text { FAR (false alarm rate) } & =c /(a+c) \\
\text { POFD (probability of false detection) } & =c /(d+c) \\
\text { ACCURACY (fraction correct) } & =(a+d) / N, \\
& \text { where } N=a+b+c+d .
\end{array}
$$

The test demonstrates to be particularly effective in identifying the non-precipitating clouds. As shown by the percentages of correct negatives, more than $90 \%$ of nonprecipitating cloudy grid cells $\left(\mathrm{RI} \leq 0.1 \mathrm{~mm} \mathrm{~h}^{-1}\right)$ for each cloud category do not satisfy the $\tau$ and $R_{\mathrm{e}}$ test and are correctly classified as non-precipitating. Conversely, the effectiveness of the test in delineating the precipitating areas, represented by the hit percentages in Table 3, depends on the cloud type. A positive result is obtained for the AVHRRAMSU-B ice precipitating clouds with $82 \%$ of success and $18 \%$ (250 grid cells out of 1387 , the total number of the ice grid cells with $\mathrm{RI}>0.1 \mathrm{~mm} \mathrm{~h}^{-1}$ ) erroneously classified as non-precipitating on the basis of the test response. It is noteworthy that $52 \%$ of these misclassified grid cells are associated with rain intensities not greater than $3 \mathrm{~mm} \mathrm{~h}^{-1}$ and $79 \%$ are classified as stratiform by the 183-WSL rain algorithm. The good performances of the $\tau$ and $R_{\mathrm{e}}$ test in discriminating between ice precipitating or non-precipitating clouds are summarized by the categorical statistics reported in Table 3; high values of POD and ACCURACY (0.820 and 0.906 , respectively), and low values of FAR and POFD $(0.161$ and 0.060$)$. For the overlapping clouds the percentage of the test success is greatly decreased (45\% of hits against $82 \%$ for the ice clouds), but as before the majority of the precipitating overlapping clouds missed by the test are associated with light rain and identified as stratiform by the rain retrieval (3097 out of 3920 grid cells do not satisfy the test). Note that the test succeeded, as demonstrated by the high ACCURACY value (0.838), even in this case of multi-layered clouds, which represents the most challenging situation due to the fact that precipitation could be not necessarily connected to the higher cloud layer, for which the $\tau$ and $R_{\mathrm{e}}$ values are retrieved from satellite (in particular $R_{\mathrm{e}}$ ). The $\tau$ and $R_{\mathrm{e}}$ test was applied also to the water clouds despite of the scarce number of these grid cell type: almost all water clouds were not identified as precipitating from the microphysical point of view (missed events are 98\%), but they are characterized by $\mathrm{RI} \leq 3 \mathrm{~mm} \mathrm{~h}^{-1}$ and classified as stratiform by the rain retrieval algorithm. It is important to note that in this case the very high value of the ACCURACY (0.991) is due only to the test effectiveness in classifying the non-precipitating water clouds (100\% of correct negatives).

Similar results were obtained by analyzing the MODISAMSR-E precipitating cloud data set. For ice clouds the performance of the $\tau$ and $R_{\mathrm{e}}$ test is worse than that for the corresponding AVHRR-AMSU-B data, with 55\% of precipitating grid cells correctly identified by the test. However, also in this case a large fraction of the grid cells that do not pass the test (4397 grid cells out of 5779) have rain intensity values lower than $3 \mathrm{~mm} \mathrm{~h}^{-1}$. Finally no water clouds are recognized as precipitating by the test, but all water clouds are associated with $\mathrm{RI} \leq 3 \mathrm{~mm} \mathrm{~h}^{-1}$. As for the ACCURACY parameter the previous comments for the AVHRR precipitating water clouds are valid. 


\section{Conclusions}

The links between the cloud characteristics and precipitation for convective storms occurred over the Mediterranean in June 2007 were studied by exploiting the cloud products from the AVHRR and the rain intensities retrieved from the AMSU-B, both onboard the NOAA-18 platform. The same case study was analysed in a previous work (Torricella et al., 2008), using the MODIS and AMSR-E data.

A test for the discrimination of the precipitating from the non-precipitating clouds was presented, inferred by the synergistic analysis of the cloud characteristics and the corresponding rain intensity values. It is based on the results obtained from the analysis of the RI versus $\tau$ and $R_{\mathrm{e}}$ scatter plots and $R_{\mathrm{e}}$ histograms for precipitating clouds, where a clear positive correlation between $\tau$ and the precipitation intensity is revealed, with a cloud optical thickness threshold value $(\sim 15)$ for the precipitation startup, and the majority of precipitating clouds showing $R_{\mathrm{e}}$ values in the [20, 30] $\mu \mathrm{m}$ range, which correspond to the heaviest precipitation with RI values up to $15 \mathrm{~mm} \mathrm{~h}^{-1}$. Analogous results were obtained from the analysis of the MODIS-AMSR-E data set, with the only difference of a $\tau$ threshold value of 40 . The test showed an appreciable capability of detecting precipitating clouds connected to convective processes and significant rain intensity values $\left(\mathrm{RI} \geq 5 \mathrm{~mm} \mathrm{~h}^{-1}\right)$, but it is completely unable to identify stratiform cloud systems producing light rain $\left(\mathrm{RI} \leq 3 \mathrm{~mm} \mathrm{~h}^{-1}\right)$, as for the emblematic case of the water clouds. Moreover, the applicability of this methodology to delineate the precipitating areas is to be considered restricted to this particular case study. Future work will be addressed to assess the test performances for further case studies, in order to refine the capability to identify precipitating convective cloud systems and to develop a strategy for identifying stratiform and water clouds connected to warm rain processes. Particularly for this cloud type, the evaluation of the relationships between cloud parameters and rain intensity will require the analysis of other case studies, mainly in tropical regions, where the number of precipitating water clouds is large enough to establish a meaningful statistic.

Furthermore the completion of this kind of analysis will require to take into account the uncertainties of the exploited cloud and precipitation data sets, associated with the particular retrieval algorithm and measurement errors, and case study characteristics. The impact of these uncertainties on the analysis results is evident also in this June 2007 case study, where, for example, the $\tau$ threshold value for the precipitation startup is dependent on the particular data set used. As specified in Sect. 5, MODIS $\tau$ values are generally greater than those retrieved from the AVHRR data, and moreover a higher number of occurrences with $\mathrm{RI}>15 \mathrm{~mm} \mathrm{~h}^{-1}$ are present in the AMSR-E data with respect to the RI data set retrieved by the 183-WSL algorithm from AMSU-B brightness temperatures, as it is evident in Fig. 5. As customary in satellite derived products disseminated by operational agen- cies or research groups, the most useful and predictive indicator of the reliability of output physical quantities values can be found in a suite of quality flags, describing the degree of the reliability of the retrieval for each observation or group of observations. In processing AVHRR, AMSR$\mathrm{E}$, and MODIS products we selected only those data having the highest degree of reliability according to the adopted retrieval schemes. However none of them encloses an error estimation on the output physical quantities, and this can be easily understood being the accuracy of the retrieval result associated with the overall status of the atmospheric column, largely unknown, and the results of validation campaigns only generically correlated with single retrieval values. There is an obvious necessity to account for the retrieval uncertainties in the statistical analysis, but there is also an inherent difficulty, or the impossibility as in this case, of finding cloud products and precipitation retrieval error (or error estimates). Only multi-instrument intensive measurements campaigns can supply the needed amount of data and ancillary observations describing the true state of the atmosphere. The validation of satellite cloud and precipitation retrieval algorithms is a very complex and still in progress activity, which requires dedicated airborne and in situ measurements to obtain the cloudy scenario characterization as well as reliable networks of rain gauges and radar to provide independent rainfall measurements. An exhaustive summary about the recent validation activities of several satellite precipitation products can be extracted from Ebert et al. (2007) and Turk et al. (2009), whereas examples of performance evaluation of cloud retrieval algorithms can be found in Nauss et al. (2005) and Ham et al. (2009).

Acknowledgements. The authors are grateful to W. Straka III, A. Heidinger and G. Vicente from NOAA-NESDIS for kindly providing the AVHRR cloud products from the CLAVR-x algorithm. Support is gratefully acknowledged from the projects AEROCLOUDS of the Italian Ministry of Education, University and Scientific Research (MIUR), Progetto Strategico "Nowcasting avanzato con l'uso di tecnologie GRID e GIS" of Regione Puglia, and EUMETSAT's Satellite Application Facility on Support to Operational Hydrology and Water Management (H-SAF).

Edited by: S. Michaelides, K. Savvidou, and F. Tymvios Reviewed by: two anonymous referees

\section{References}

Ebert, E. E., Janowiak, J. E., and Kidd, C.: Comparison of nearreal-time precipitation estimates from satellite observations and numerical models, B. Am. Meteorol. Soc., 88, 47-64, 2007.

Ebert, E. E.: WWRP/WGNE Joint Working Group on Verification. Forecast verification - Issues, methods and FAQ, available at: http://www.cawcr.gov.au/projects/verification/(last access: 23 December 2009), 2005. 
Ham, S.-H., Sohn, B.-J., Yang, P., and Baum, B. A.: Assessment of the quality of MODIS cloud products from radiance simulations, J. Appl. Meteorol. Clim., 48, 1591-1612, 2009.

Heidinger, A. K.: Rapid daytime estimation of cloud properties over a large area from radiance distributions, J. Atmos. Ocean. Tech., 20, 1237-1250, 2003.

Laviola, S. and Levizzani, V.: Rain retrieval using the $183 \mathrm{GHz}$ absorption lines, in: IEEE Proc. MicroRad, 10th Specialist Meeting Radiometry and Remote Sensing of Environment, Firenze, doi:10.1109/MICRAD.2008.4579505, 11-14 March 2008a.

Laviola, S. and Levizzani, V.: Observing precipitation with AMSU-B opaque channels: the 183-WSL algorithm, 4th IPWG Workshop, Beijing, 13-17 October 2008b.

Nauss, T., Thies, B., Turek, A., Bendix, J., and Kokhanovsky, A.: Operational discrimination of raining from non-raining clouds in mid-latitudes using multispectral satellite data, in: Precipitation: Advances in measurement, estimation and prediction, edited by: Michaelides, S., Springer, 171-194, 2008.

Nauss, T., Kokhanovsky, A. A., Nakjima, T. Y., Reudenbach, C., and Bendix, J.: The intercomparison of selected cloud retrieval algorithms, Atmos. Res., 78, 46-78, 2005.
Pavolonis, M. J., Heidinger, A. K., and Uttal, T.: Daytime global cloud typing from AVHRR and VIIRS: Algorithm description, validation, and comparisons, J. Appl. Meteorol., 44, 804-826, 2005.

Stephens, G. L. and Kummerow, C. D.: The remote sensing of clouds and precipitation from space: A review, J. Atmos. Sci., 64, 3742-3765, 2007.

Thoss, A., Dybbroe, A., and Bennartz, R.: The Nowcasting SAF Precipitating Clouds Products, Proccedings of the 2001 EUMETSAT Satellite Data User's Conference, Antalya, Turkey, 1-5 October 2001.

Torricella, F., Cattani, E., and Levizzani, V.: Rain area delineation by means of multispectral cloud characterization from satellite, Adv. Geosci., 17, 43-47, 2008, http://www.adv-geosci.net/17/43/2008/.

Turk, F. J., Sohn, B.-J., Oh, H.-J., Ebert, E. E., Levizzani, V., and Smith, E. A.: Validating a rapid-update satellite precipitation analysis across telescoping space and time scales, Meteorol. Atmos. Phys., 105, 99-108, 2009. 